\title{
Optimal process for the extraction and identification of flavonoids from the leaves of Polyalthia longifolia using $\mathrm{L}_{16}$ Orthogonal design of experiment
}

\author{
T. SATHISH KUMAR *, M. SAMPATH, S. V. SIVACHANDRAN, \\ S. SHANMUGAM and P. RAJASEKARAN \\ Department of Biotechnology, Kumaraguru College of Technology, Coimbatore-641 006, Tamil Nadu, India. \\ ${ }^{*}$ Corresponding author, E-mail: sathishkumart29@gmail.com
}

\begin{abstract}
The study has been carried out to investigate the effects of single factors such as temperature, extraction time, concentration of ethanol, material ratio and no. of extractions on the contents of flavonoids present in the leaves of Polyalthia longifolia. On this basis, an $\mathrm{L}_{16}$ orthogonal design of experiment was used to determine the optimal conditions for the extraction of flavonoids. The amount of flavonoids extracted reached its maxima at $65{ }^{\circ} \mathrm{C}$ for $2 \mathrm{hrs}$ by using 75\% ethanol (modifier) with a material ratio of $1: 10$ and 2 times of extraction. The TLC performed for the optimal extracts showed the presence of rutin and quercetin related compounds.

(C) 2009 International Formulae Group. All rights reserved.
\end{abstract}

Keywords: Annonaceae, Flavonoids, Orthogonal experiments, Single-factor experiments, Polyalthia longifolia.

\section{INTRODUCTION}

A medicinal plant is any plant which, in one or more of its organ, contains substance that can be used for therapeutic purpose or which is a precursor for synthesis of useful drugs. Although there are no apparent morphological characteristics in the medicinal plants growing with them, yet they possess some special qualities that make them medicinally important. It has now been established that the plants which naturally synthesis and accumulate some secondary metabolites, like alkaloids, flavonoids, glycosides, tannins, and volatile oils, possess medicinal properties.

Flavonoids are the most important and prominent phenolic compounds that are known for their antioxidant and free radical scavenging activity (Van Acker et al., 1996). They have been referred to as "nature's biological response modifiers" because of strong experimental evidence of their inherent ability to modify the body's reaction to allergens, viruses, and carcinogens. They possess anti-allergic, anti-inflammatory, antimicrobial and anti-cancer activity (Cushnie and Lamb, 2005). Consumers and food manufacturers have become interested in flavonoids for their medicinal properties, especially their potential role in the prevention of cancer and cardiovascular diseases.

In many cases, it is highly difficult to find quickly the suitable experimental conditions for a given separation task. Prediction of separation conditions is not yet straightforward. Therefore, good experimental design becomes increasingly important. Orthogonal array can be defined as a matrix with the columns representing the number of parameters to be studied with their different levels in different combinations of experiments and the number of rows equal to the number of experiments (Siva Hemalatha et al., 2007). Orthogonal design which only 
focuses on the main effects of the factors, allows the number of experiments to be drastically reduced. In separation science, this kind of experimental design has already shown its usefulness in liquid chromatography and capillary electophoresis (Hu Zhide et al., 2002).

Polyalthia longifolia (Sonn.) Thwaites (Family: Annonaceae) is a tall handsome evergreen tree and cultivated all over India. Ethanobotanically, Polyalthia longifolia is used as anti-cancer, anti-inflammatory, analgesic, hepatoprotective, antiulcer and antihyperglycaemic agents (Malairajan et al., 2006). It is also used to treat anti-helmintic and kidney diseases. The Polyalthia genus has been investigated phytochemically and was reported to contain alkaloids, flavonoids, acetogenin and triterpenoids (Padmaa Paarakh and Khosa, 2009). Chromatographic analysis of the methanol extract of Polyalthia longifolia also revealed the presence of steroids, alkaloids, biterpenoids, carbohydrates, amino acids, essential oil, phenolics and flavonoids as major phytochemicals (Anupam Ghosh et al., 2008). Previous reports are there for the presence of several cytotoxic compounds like halimane diterpene, $3 \beta, 5 \beta, 16 \alpha$-trihydroxyhalima-13(14)-en-15,16olide and a new oxoprotoberberine alkaloid, (-)-8-oxopolyalthiaine from Polyalthia longifolia var. pendula (Yang-Chang Wu et al., 2000). Similarly, the ethanolic leaf extract of Polyalthia longifolia possess a potent nitric oxide radical scavenging activity (Moni Rani Saha et al., 2008).

In spite of several scientific documentation, so for no work has been progressed in investigating the optimization of flavonoids extraction from the leaves of this plant. So our laboratory has focused in determining the optimal conditions for the extraction using $\mathrm{L}_{16}$ orthogonal design of experiment.

\section{MATERIALS AND METHODS Plant material}

The plant leaves were collected from the medicinal garden of Kumaraguru College of Technology, Coimbatore, India. The species was identified, confirmed by Botanical Survey of India (BSI), Southern Circle, Coimbatore, India. The voucher specimen (No. SAM 01) was deposited at
Department of Biotechnology, Kumaraguru College of Technology, Coimbatore, Tamilnadu, India.

\section{Extraction process}

The main factors that affect the extraction of flavonoids like temperature, extraction time, materials ratio, extracting agent $(\%)$ and the no. of extractions were studied separately. The optimum extraction conditions were then determined by $\mathrm{L}_{16}$ orthogonal design of experiment (Table 1). A single factor analysis of variance (One way ANOVA) was espoused to investigate the effect of each factor in the extraction of flavonoids.

\section{Estimation of total flavonoids content (TFC) \\ Total flavonoids content (TFC) was} estimated spectrophotometrically (Beckman DU 530 UV/Vis spectrophotometer, USA) with slight modifications (Zhishen et al., 1999). About $0.1 \mathrm{ml}$ of the leaf extract added $4.9 \mathrm{ml}$ of distilled water and $0.3 \mathrm{ml} 5 \%$ $\mathrm{NaNO}_{2}$. $3 \mathrm{ml}$ of $10 \% \quad \mathrm{AlCl}_{3}$ was added 5 minutes later. After 6 minutes, $2 \mathrm{ml}$ of $1 \mathrm{M}$ $\mathrm{NaOH}$ was added and the absorbance was measured at $510 \mathrm{~nm}$. Rutin was used as a standard for constructing a calibration curve. Data were reported as mean \pm SD for three replicate measurements.

\section{Identification of flavonoids by thin layer chromatography (TLC)}

Chromatographies of the optimized extracts were run one dimensionally in the mobile phase solvent (ethyl acetate - water ethanol, 5:5:1, v/ v/ v) at room temperature of $25^{\circ} \mathrm{C}$. The concentrated extracts $(50 \mu \mathrm{l})$ were spotted on the lower left of the TLC plate and the diameter of the spot in each chromatogram was normally about $5 \mathrm{~mm}$. Authentic markers of flavonol (quercetin) and flavonoid glycoside (rutin) obtained commercially were co-chromatographed. Identification of the flavonoids in the extracts was done under far UV light after the application of ammonia as spraying agent (Adam et al., 2002; Guorong et al., 2006).

\section{RESULTS}

The optimal conditions for the extraction of flavonoids was found to be at 65 
${ }^{\circ} \mathrm{C}, 2 \mathrm{hrs}$ extraction duration, $75 \%$ ethanol, 1:10 material ratio and 2 times of extraction (Table 2). The investigation proved that the temperature was found to be a major factor that affects the extraction procedure of flavonoids. Moreover, the TLC results of the optimized extracts revealed the presence of quercetin and rutin related compounds (Figure 5 and Figure 6).

\section{DISCUSSION}

Flavonoids are a large family of polyphenolic compounds synthesized by plants (Beecher, 2003). Scientists are interested in the potential health benefits of flavonoids especially as nutraceuticals associated with fruits and vegetable-rich diets. Many of the biological effects of flavonoids appear to be related to their ability to modulate cell-signaling pathways (Williams et al., 2004), rather than their antioxidant activity. Higher intakes of flavonoid rich foods have been associated with reduced risk of various chronic diseases (Hirvonen et al., 2001), coronary heart disease (Knekt et al., 2002), cardiovascular disease (Yochum et al., 1999) and neurodegenerative diseases (Ramassamy, 2006). Various reports exist about the flavonoids action on the inhibition of the development of chemically-induced cancers in animal models of lung ( Yang et al., 1998), oral (Balasubramanian and Govindasamy, 1996), esophageal (Li et al., 2002), stomach (Yamane et al., 1996), colon (Guo et al., 2004), skin (Huang et al., 1997), prostate (Gupta et al., 2001; Haddad et al., 2006) and breast cancer (Yamagishi et al., 2002). Previous reports for the extraction optimization of flavonoids from the leaves of Tabernaemontana heyneana Wall has revealed that a Solid: liquid ratio of 1:05 for 2 hours at $85{ }^{\circ} \mathrm{C}$ was required for higher yield (Sathishkumar et al., 2008).

\section{Effect of temperature on the extraction of flavonoids}

Figure 1 showed the contents of raw flavonoids increasing gradually with a rise in the temperature from $55^{\circ} \mathrm{C}$ to $85{ }^{\circ} \mathrm{C}$. The contents of flavonoids gradually increased with an interval of $10{ }^{\circ} \mathrm{C}$. It may be plausible that the greater speed of the molecule movements may be facilitated at higher temperature so that the flavonoids diffused more quickly from cell to extracting agent. But the flavonoids could be oxidized if the temperature exceeds $80{ }^{\circ} \mathrm{C}$ and as a result the contents of flavonoids extracted will start to decrease gradually (Yaqin et al., 2005). Temperature's effect on extraction is dual. On one hand, higher temperature can accelerate the solvent flow and thus increase the flavonoids content and on the other hand, it can decrease the fluid density that may reduce the extraction efficiency (He Guo-qing et al., 2005). The overall analysis revealed that 65 ${ }^{\circ} \mathrm{C}$ was the optimum temperature for the extraction of raw flavonoids.

\section{Effect of flavonoids extraction time}

The result of Figure 2 showed that the contents of flavonoids extracted for $2 \mathrm{hrs}$ reached maxima and prolonged extraction may not yield an increased content. Furthermore a decrease in the flavonoids content was noticed for $3 \mathrm{hrs}$ extraction and a sudden increase in their content was observed for $4 \mathrm{hrs}$ extraction time. This increase in the flavonoids content may be due to the synergistic effect of other parameters involved.

\section{Effect of material ratio on the extraction of flavonoids}

Figure 3 showed at 1:10 material ratio the contents of raw flavonoids extracted reached the maxima. Further increase in the material ratio leads to a gradual decrease in the flavonoids content resulting in a saturated condition. This decrease might be due to the fact that when the material ratio reached a certain level, the extract was well dissolved in the solution that may lead the contents of the extract become saturated and prevent further increase (Yaqin et al., 2005).

\section{Effect of extracting agent (ethanol) on the extraction of flavonoids}

The result of Figure 4 revealed that the contents of raw flavonoids extract increases with the concentration of ethanol i.e., $65 \%$ and $75 \%$. On further increase in the ethanol concentration, i.e., beyond $75 \%$ leads to a decrease in the flavonoids content. Among various solvents, ethanol was selected as a right choice because it is environmentally benevolent and comparatively safe to human health (He Guo-qing et al., 2005). Generally, 


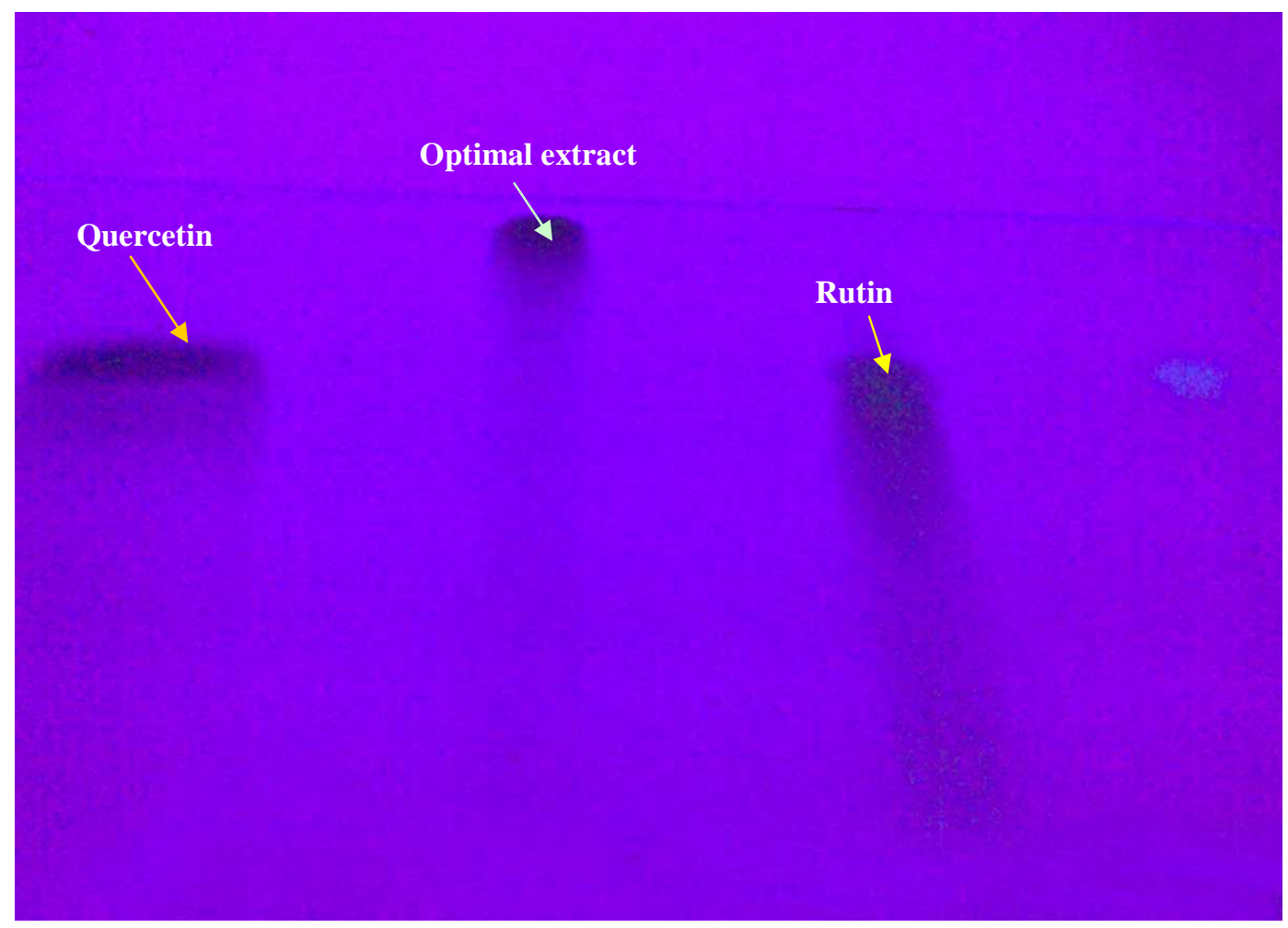

Figure 5: Identification of flavonoids from optimised extract by TLC under Far UV light.

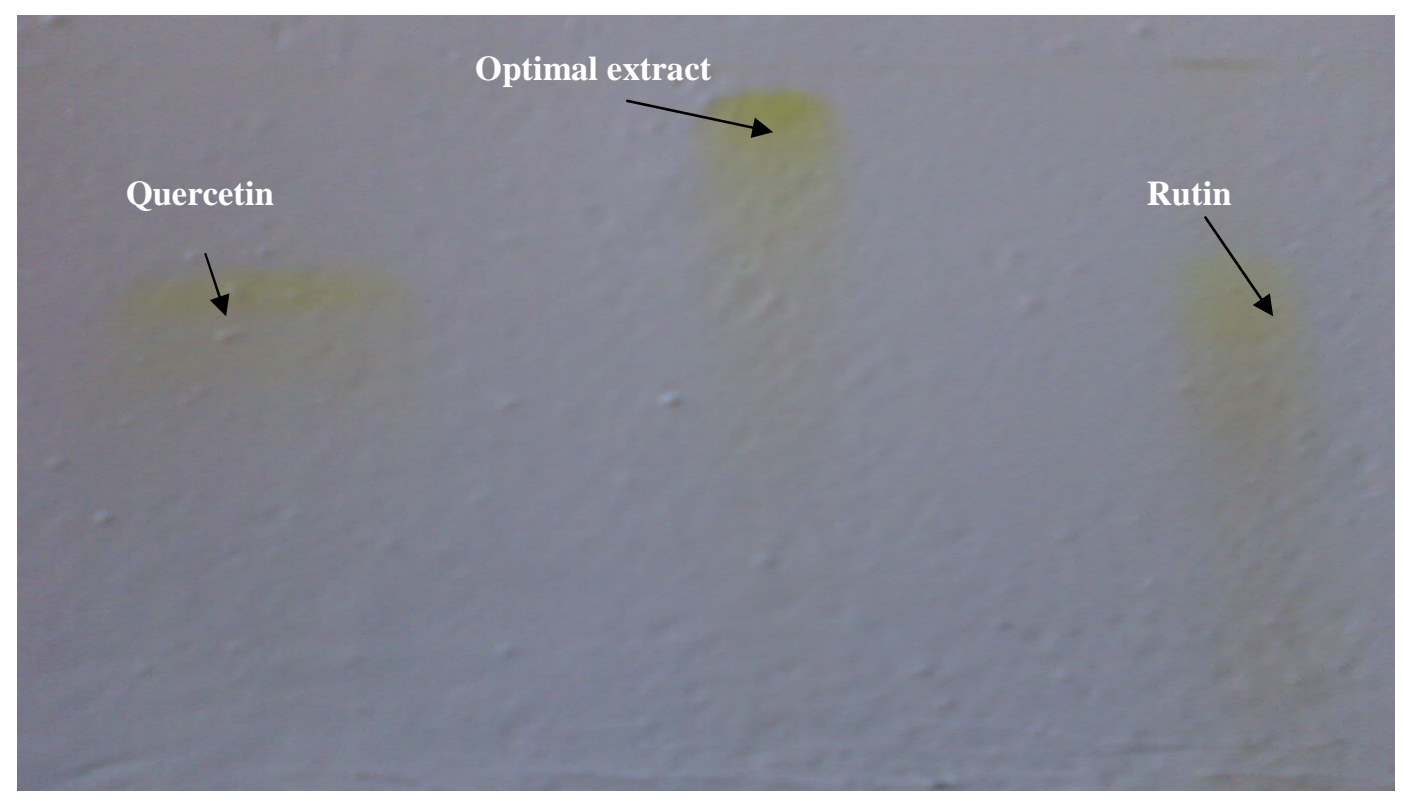

Figure 6: Identification of rutin related compounds by TLC under visible light (Enlarged image using Iflex image vision). 


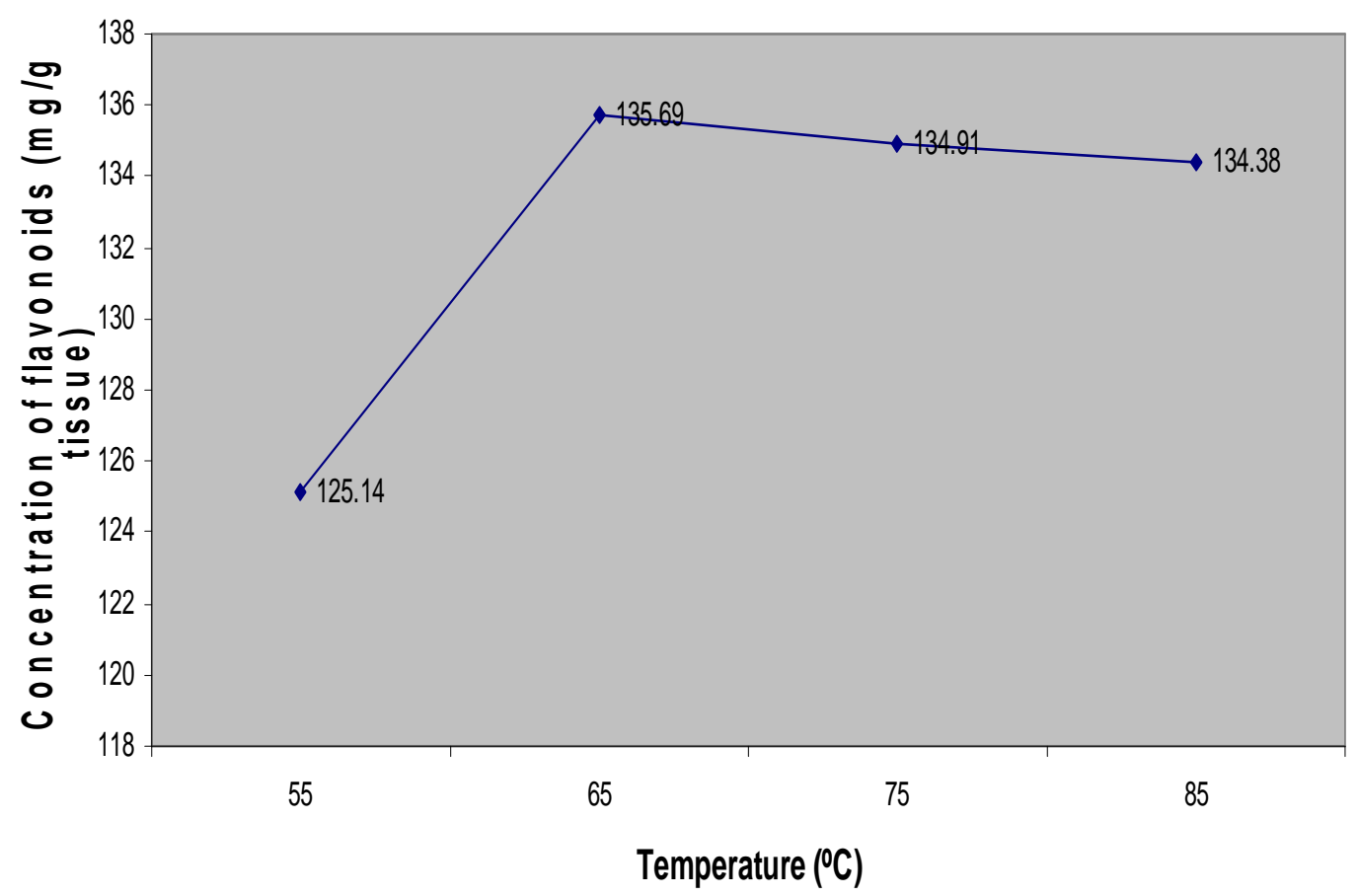

Figure 1: Effect of temperature on flavonoids extraction.

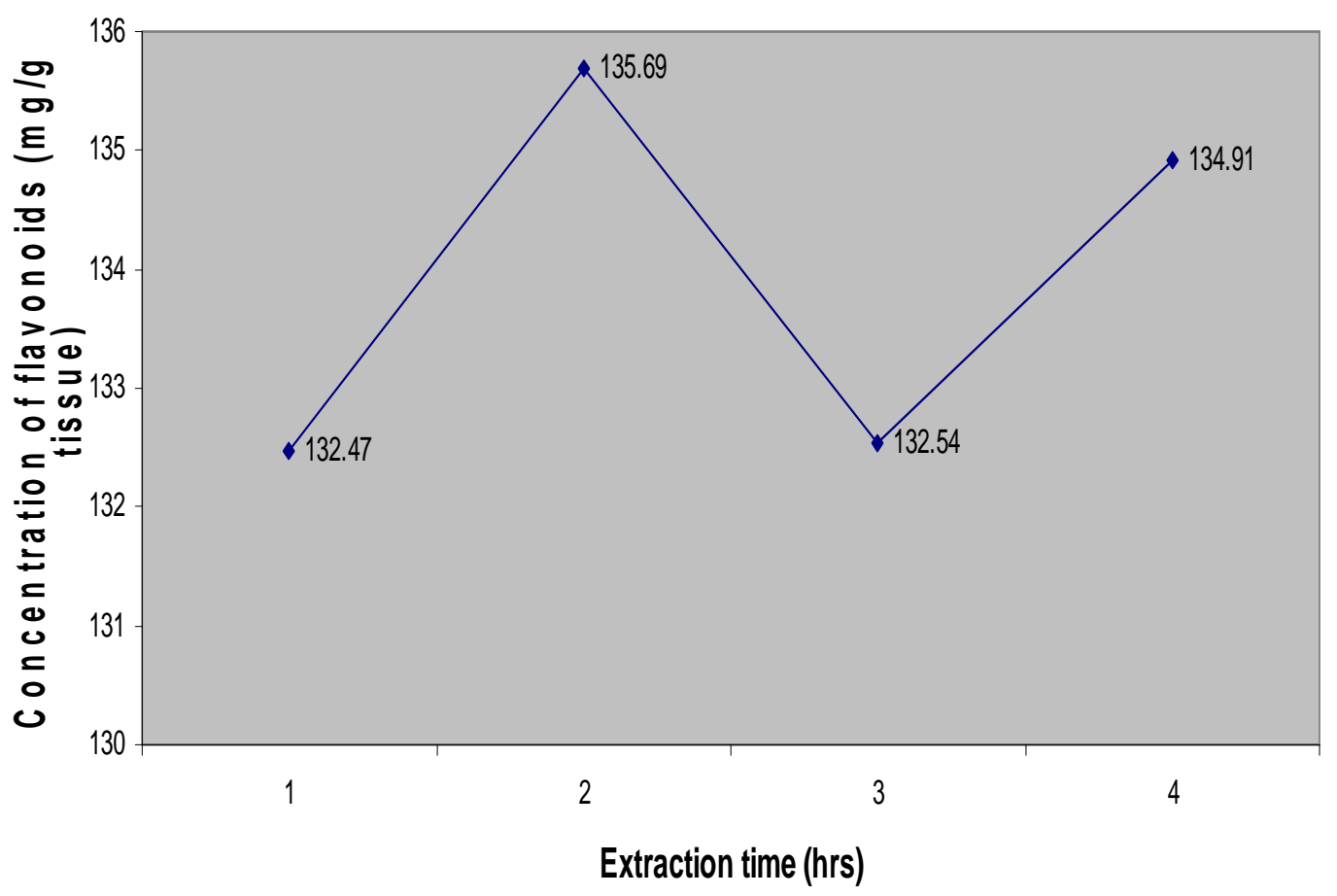

Figure 2: Effect of different extraction time. 


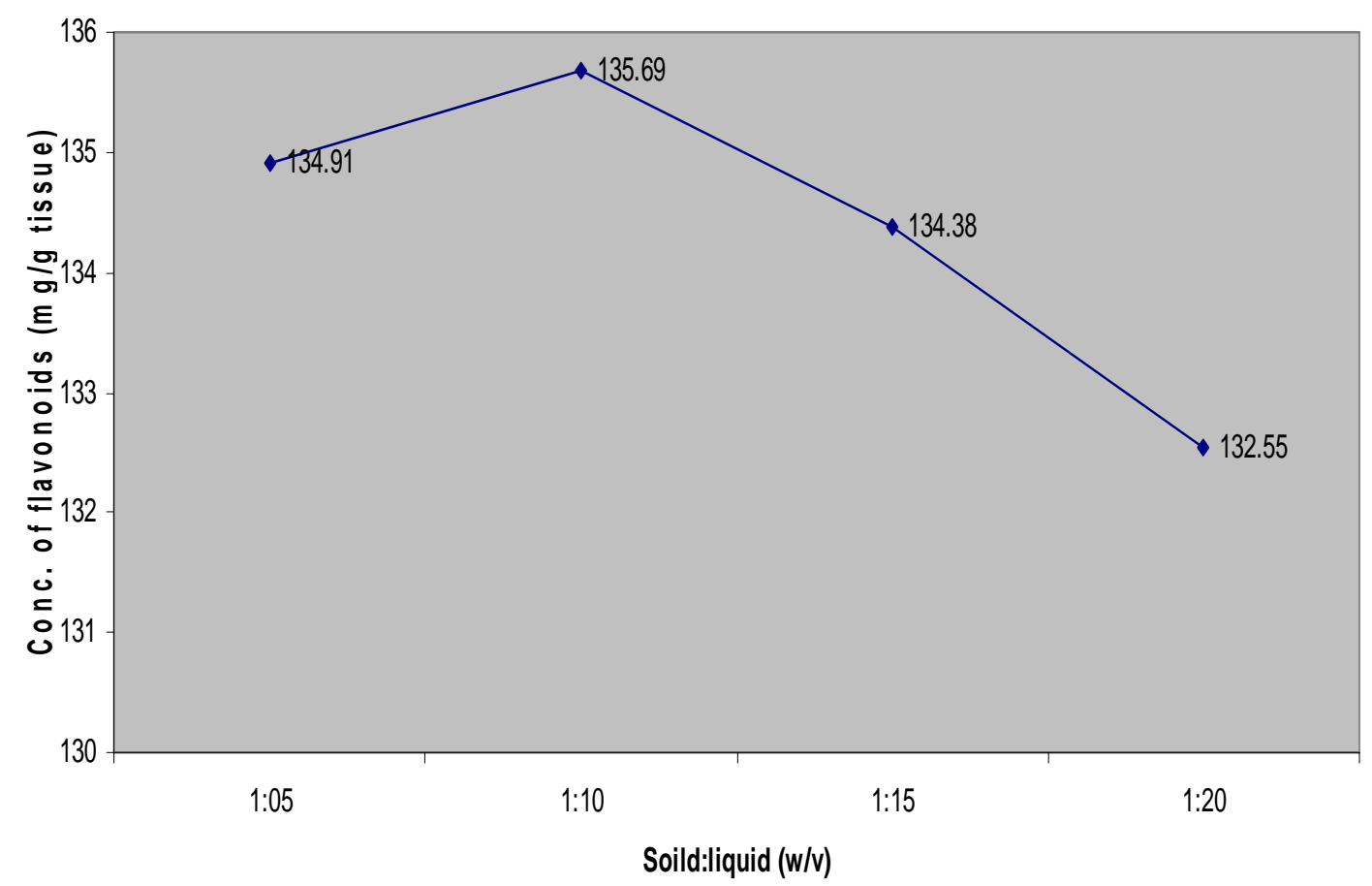

Figure 3: Effect of solid: liquid (w/v) in the extraction of flavonoids. Conc.: Concentration.

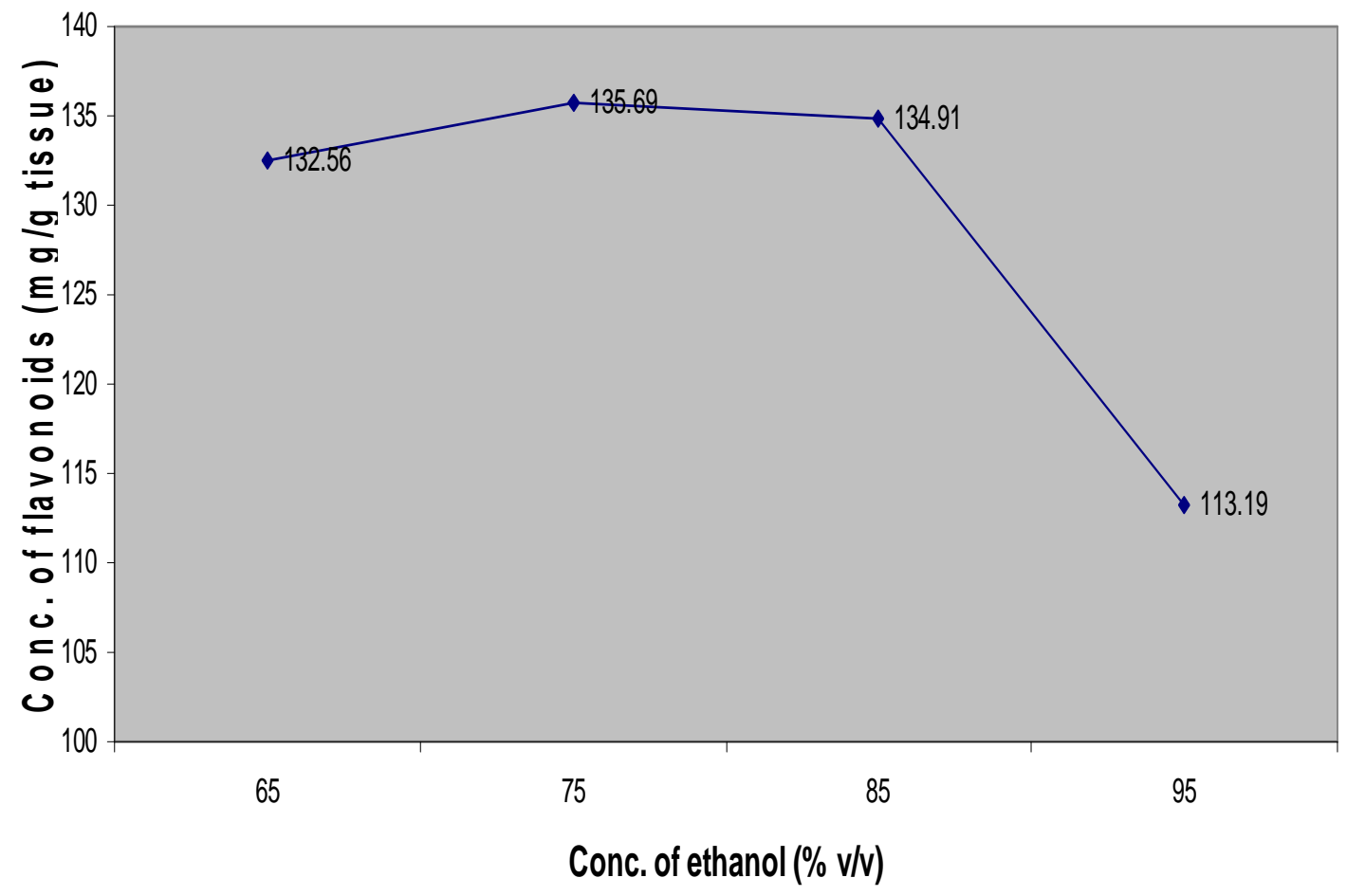

Figure 4: Effect of ethanol on the extraction of flavonoids. Conc.: Concentration. 
Table 1: Factors for the extraction of flavonoids.

\begin{tabular}{lccccc}
\hline \multirow{2}{*}{ Levels } & $\mathbf{A}$ & $\mathbf{B}$ & $\mathbf{C}$ & $\mathbf{D}$ & $\mathbf{E}$ \\
\cline { 2 - 6 } & $\begin{array}{c}\text { Temperature } \\
\left({ }^{\mathbf{}} \mathbf{C}\right)\end{array}$ & $\begin{array}{c}\text { Extract time } \\
(\mathbf{h r s})\end{array}$ & $\begin{array}{c}\text { Solvent } \\
(\boldsymbol{\%})\end{array}$ & $\begin{array}{c}\text { Solid : Liquid } \\
(\mathbf{W}: \mathbf{V})\end{array}$ & No. of extraction \\
\hline 1 & 55 & 1 & 65 & $1: 5$ & 1 \\
2 & 65 & 2 & 75 & $1: 10$ & 2 \\
3 & 75 & 3 & 85 & $1: 15$ & 3 \\
4 & 85 & 4 & 95 & $1: 20$ & 4 \\
\hline
\end{tabular}

Table 2: $\mathrm{L}_{16}$ orthogonal design of experiment (Chen et al., 2007).

\begin{tabular}{lccccc}
\hline Experiments & A & B & C & D & E \\
\hline 1 & 1 & 1 & 2 & 3 & 4 \\
2 & 1 & 2 & 1 & 4 & 3 \\
3 & 1 & 3 & 4 & 1 & 2 \\
4 & 1 & 4 & 3 & 2 & 1 \\
5 & 2 & 1 & 1 & 1 & 1 \\
6 & 2 & 2 & 2 & 2 & 2 \\
7 & 2 & 3 & 3 & 3 & 3 \\
8 & 2 & 4 & 4 & 4 & 4 \\
9 & 3 & 1 & 3 & 4 & 2 \\
10 & 3 & 2 & 4 & 3 & 1 \\
11 & 3 & 3 & 1 & 2 & 4 \\
12 & 3 & 4 & 2 & 1 & 3 \\
13 & 4 & 1 & 4 & 2 & 3 \\
14 & 4 & 2 & 3 & 1 & 4 \\
15 & 4 & 3 & 2 & 4 & 1 \\
16 & 4 & 4 & 1 & 3 & 2 \\
\hline
\end{tabular}

ethanol acts as a potent modifier of cell membrane properties, especially in altering the permeability nature for solutes. Ethanol interacts with the flavonoids probably through non-covalent interactions and promotes a rapid diffusion into the solution (Luque de Castro and Tena, 1996). Various concentration of ethanol used exhibited different effect in changing the fluid polarity and thus has diversed effect on the solubility enhancement of the flavonoids (He Guo-qing et al., 2005). The optimal extraction yield may be fulfilled when the polarity of the fluid and its flavonoids are coincident. In this study, the results indicated $75 \%$ ethanol was found to be optimal for extracting the flavonoids.

\section{Effect of No. of extractions on flavonoids}

The contents of raw flavonoids extract increases with the number of extractions. Obviously, when the number of extraction times increases, the yield of the respective bioactive principle may be increased (Chen et al., 2007). In this investigation, the raw flavonoids content was increased by 2 times of the extraction.

\section{Optimization of flavonoids extraction using $\mathrm{L}_{16}$ orthogonal design}

The parameters and the orthogonal design of experiment for the extraction of flavonoids were given in the Table 1 and Table 2. The results were made in the form of range analysis and one way ANOVA by Sigmastat 3.5 software. The results were depicted in Table 3 and Table 4. The order of the effect of factors on flavonoids extraction was $\mathrm{A}>\mathrm{D}>\mathrm{E}>\mathrm{B}>\mathrm{C}$. The temperature parameter was observed to possess a greatest effect on the extraction procedure and the material ratio was found to be a secondary parameter even though it was not proved to be a significantly different at 5\% level. The other factors such as solvent (\%), extraction duration and no. of extractions may not play a vital role in extracting the flavonoids to a higher yield. 
Table 3: Experimental results and range analysis.

\begin{tabular}{ccccccc}
\hline Experiments & $\mathbf{A}$ & $\mathbf{B}$ & $\mathbf{C}$ & $\mathbf{D}$ & $\mathbf{E}$ & Flav. (mg/g) \\
\hline 1 & 1 & 1 & 2 & 3 & 4 & 113.19 \\
2 & 1 & 2 & 1 & 4 & 3 & 108.48 \\
3 & 1 & 3 & 4 & 1 & 2 & 125.14 \\
4 & 1 & 4 & 3 & 2 & 1 & 77.96 \\
5 & 2 & 1 & 1 & 1 & 1 & 132.47 \\
6 & 2 & 2 & 2 & 2 & 2 & 135.69 \\
7 & 2 & 3 & 3 & 3 & 3 & 86.34 \\
8 & 2 & 4 & 4 & 4 & 4 & 46.23 \\
9 & 3 & 1 & 3 & 4 & 2 & 69.76 \\
10 & 3 & 2 & 4 & 3 & 1 & 84.06 \\
11 & 3 & 3 & 1 & 2 & 4 & 50.40 \\
12 & 3 & 4 & 2 & 1 & 3 & 134.91 \\
13 & 4 & 1 & 4 & 2 & 3 & 111.89 \\
14 & 4 & 2 & 3 & 1 & 4 & 113.02 \\
15 & 4 & 3 & 2 & 4 & 1 & 132.56 \\
16 & 4 & 4 & 1 & 3 & 2 & 134.38 \\
$\mathrm{~K}_{1}$ & 53.2 & 64.8 & 84.6 & 104.7 & 90.2 & \\
$\mathrm{~K}_{2}$ & 63.3 & 80.4 & 85.3 & 80.5 & 62.8 & \\
$\mathrm{~K}_{3}$ & 94.8 & 66.4 & 77.7 & 82.7 & 82.3 & \\
$\mathrm{~K}_{4}$ & 109.9 & 88.8 & 73.5 & 53.3 & 85.9 & \\
$\mathrm{k}_{1}$ & 13.3 & 16.2 & 21.2 & 26.2 & 22.6 & \\
$\mathrm{k}_{2}$ & 15.8 & 20.1 & 21.3 & 20.1 & 15.7 & \\
$\mathrm{k}_{3}$ & 23.7 & 16.6 & 19.4 & 20.7 & 20.6 & \\
$\mathrm{k}_{4}$ & 27.5 & 22.2 & 18.4 & 13.3 & 21.5 & \\
\hline $\boldsymbol{R}$ & $\mathbf{1 4 . 2}$ & $\mathbf{6 . 0}$ & $\mathbf{2 . 8}$ & $\mathbf{1 2 . 9}$ & $\mathbf{6 . 9}$ & \\
\hline $\mathbf{K}=$ Values obtained from individual factors (Temperature, Ext. time etc.,), R= Rank.
\end{tabular}

Table 4: One way ANOVA levels.

\begin{tabular}{lcccc}
\hline Levels & Sum of square & Degrees of freedom & Mean square & F-value \\
\hline A & 2955.58 & 3 & 985.19 & 2.96 \\
B & 431.13 & 3 & 143.71 & 0.15 \\
C & 4318.01 & 3 & 1439.33 & 2.23 \\
D & 3272.56 & 3 & 1090.85 & 0.15 \\
E & 3052.92 & 3 & 1017.64 & 1.34 \\
& & 15 & & \\
\hline
\end{tabular}

\section{Conclusion}

It was concluded that by using $\mathrm{L}_{16}$ orthogonal design of experiment the optimal conditions for the extraction of flavonoids was proved to be at $65{ }^{\circ} \mathrm{C}, 2 \mathrm{hrs}$ extraction duration, $75 \%$ ethanol, 1:10 material ratio and 2 times of extraction. The results proved that the temperature was found to be a major factor that affects the extraction procedure of flavonoids. Moreover, the TLC results of the optimized extracts were proved to contain quercetin and rutin related compounds. In future, further work may be attempted and extended for purifying the flavonoids and elucidating their structures which may be responsible for various applications.

\section{ACKNOWLEDEGEMENTS}

The authors wish to express their gratitude to the Management of Kumaraguru College of Technology, India for their valuable support to carry out this research project. 


\section{REFERENCES}

Adam JH, Ramian Omar, Wilcock CC. 2002. Phytochmeical screening of flavonoids in three hybrids of Napenthes (Napenthaceae) and their putative parental species from Sarawak and Sabah. Online J. Biol. Sci., 2(9): 623-625.

Anupam Ghosh, Bidus Kanti Das, Soroj Kumar Chatterjee, Goutam Chandra. 2008. Antibacterial potentiality and phytochemical analysis of mature leaves of Polyalthia longifolia (Magnoliales: Annonaceae). S. P. J. Nat. Sci., 26: 6872.

Balasubramanian S, Govindasamy S. 1996. Inhibitory effect of dietary flavonol quercetin on 7, 12-dimethylbenz [a]anthracene-induced hamster buccal pouch carcinogenesis. Carcinogenesis, 117(4): 877-879.

Beecher GR. 2003. Overview of dietary flavonoids: nomenclature, occurrence and intake. J. Nut., 133(10): 3248-3254.

Chen XQ, Wu SD, Jiang XY, Chen QY 2007. Comparison of techniques for the extraction of the hypotensive drugs geniposidic acid and geniposide from Eucommia ulmoides. J. Iran Chem. Soc., 4(2): 205-214.

Cushnie TPT, Lamb AJ. 2005. Antimicrobial activity of flavonoids. Int. J. Antimicro Agents, 26(5): 343-356.

Guorong F, Jinyong P, Yutian W. 2006. Preparative separation and isolation of three flavonoids and three phloroglucinol derivatives from Hypericum japonicum Thumb. using high-speed countercurrent chromatography by stepwise increasing the flow rate of the mobile phase. J. Liq. Chromato., 29: 1619-1632.

Guo JY, Li X, Browning JD. 2004. Dietary soy isoflavones and estrone protect ovariectomized ERalphaKO and wildtype mice from carcinogen-induced colon cancer. J. Nut., 134(1): 179-182.

Gupta S, Hastak K, Ahmad N, Lewin JS, Mukhtar H. 2001. Inhibition of prostate carcinogenesis in TRAMP mice by oral infusion of green tea polyphenols. Pro. Nat. Aca. Sci., 98(18): 10350-10355.

Haddad AQ, Venkateswaran V, Viswanathan L, Teahan SJ, Fleshner NE, Klotz LH. 2006. Novel antiproliferative flavonoids induce cell cycle arrest in human prostate cancer cell lines. Pros. Can. Pro. Dis., 9(1): 68-76.

He Guo-qing, Xiong Hao-ping, Chen Qi-he, Ruan Hui, Wang Zhao-yue, Traore Lonseny. 2005. Optimization of conditions for supercritical fluid extraction of flavonoids from hops (Humulus lupulus L). J. Zhejiang Univ Sci., 6B(10): 999-1004.

Hirvonen T, Pietinen P, Virtanen M. 2001. Intake of flavonols and flavones and risk of coronary heart disease in male smokers. Epidemiol., 12(1): 62-67.

Huang MT, Xie JG, Wang ZY. 1997. Effects of tea, decaffeinated tea, and caffeine on UVB light-induced complete carcinogenesis in SKH-1 mice: demonstration of caffeine as a biologically important constituent of tea. Can. Res., 57(13): 2623-2629.

$\mathrm{Hu}$ Zhide, Liu Huitao, Wang Ketai, Xu Hongping, Chen Xinggu. 2002. Application of experimental design and artificial neural networks to separation and determination of active components in traditional chinese medicinal preparations by capillary electrophoresis. Chromatographia, 55: 579-583.

Knekt P, Kumpulainen J, Jarvinen R. 2002. Flavonoid intake and risk of chronic diseases. Am. J. Clin Nut., 76(3): 560568.

Li ZG, Shimada Y, Sato F. 2002. Inhibitory effects of epigallocatechin-3-gallate on $\mathrm{N}$-nitrosomethylbenzylamine-induced esophageal tumorigenesis in F344 rats. Int. J. Oncol., 21(6): 1275-1283.

Luque de Castro MD, Tena MT. 1996. Strategies for supercritical fluid extraction of polar and ionic compounds. Trends Anal. Chem., 15: 32-37.

Malairajan P, Geetha Gopalakrishnan G, Narasimhan S, Jessi Kala Veniz. 2006. Analgesic activity of some Indian medicinal plants. J. Ethnopharm., 106(3): 425-428.

Moni Rani Saha, Rumana Jahangir, Md. Mynol Islam Vhuiyan, Israt Jahan Biva. 2008. In vitro nitric oxide scavenging activity of ethanol leaf extracts of four Bangladeshi medicinal plants. $S . \quad J$. Pharm. Sci., 1(1 \& 2): 57-62.

Padmaa M, Paarakh RL, Khosa. 2009. Phytoconstituents from the genus 
Polyalthia - a review. J. Pharm. Res., 2(4): 594-605.

Ramassamy C. 2006. Emerging role of polyphenolic compounds in the treatment of neurodegenerative diseases: a review of their intracellular targets. Eur. J. Pharmacol., 545(1): 51-64.

Sathishkumar T, Baskar R, Shanmugam S, Rajasekaran P, Sadasivam S, Manikandan V. 2008. Optimization of flavonoids extraction from the leaves of Tabernaemontana heyneana wall. using $\mathrm{L}_{16}$ Orthogonal design. Nat. Sci., 6(3): 10-21.

Siva Hemalatha, Vivekananda Mandal and Yogesh Mohan. 2007. Optimization of curcumin extraction by microwave assisted in vitro plant cell bursting by orthogonal array designed extraction process and HPTLC analysis. Phcog. Mag., 3(11): 132-138.

Van Acker SA, De Groot MJ, Van den Berg DJ, Tromp MN, Donne Op den Kelder G, Van der Vijgh WJ, Bast A. 1996. A quantum chemical explanation of the antioxidant activity of flavonoids. Chem. Res. Toxicol., 9: 1305-1312.

Williams RJ, Spencer JP, Rice-Evans C. 2004. Flavonoids: antioxidants or signalling molecules. Free Rad. Biol. Med., 36(7): 838-849.

Yamagishi M, Natsume M, Osakabe N. 2002. Effects of cacao liquor proanthocyanidins on PhIP-induced mutagenesis in vitro, and in vivo mammary and pancreatic tumorigenesis in female Sprague-Dawley rats. Can. Let., 185(2): 123-130.

Yamane T, Nakatani H, Kikuoka N. 1996. Inhibitory effects and toxicity of green tea polyphenols for gastrointestinal carcinogenesis. Cancer, 77(8): 1662-1667.

Yang CS, Yang GY, Landau JM, Kim S, Liao J. 1998. Tea and tea polyphenols inhibit cell hyperproliferation, lung tumorigenesis, and tumor progression. Exp. Lung Res., 24(4): 629-639.

Yang-Chang $\mathrm{Wu}$, Chung-Yi Chen, Fang-Rong Chang, Yao-Ching Shih, Tian-Jye Hsieh, Yi-Chen Chia, Huang-Yi Tseng,' HuaChien Chen, Shu-Jen Chen, Ming-Chu Hsu. 2000. Cytotoxic Constituents of Polyalthia longifolia var. Pendula. J. Nat. Prod., 63(11): 1475-1478.

Yaqin Xu, Rui Zhang, Hong Fu. 2005. Studies on the optimal process to extract flavonoids from red-raspberry fruits. Nat. Sci., 3(2): 43-46.

Yochum L, Kushi LH, Meyer K, Folsom AR. 1999. Dietary flavonoid intake and risk of cardiovascular disease in postmenopausal women. Am. J. Epidemiol., 149(10): 943949.

Zhishen J, Mengcheng T, Jianming W. 1999. The determination of flavonoids contents in mulberry and their scavenging effects on superoxide radicals. Food Chem., 64: $555-559$. 